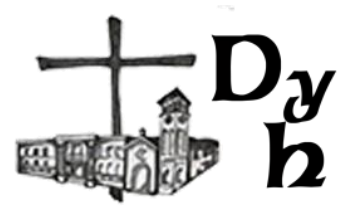

\title{
LETRAS DE PIRONIO
}

\author{
Pironio's Writings \\ Leonardo Javier Ponce \\ leojavierponce@gmail.com \\ Seminario Mayor San José - La Plata - Argentina
}

\section{Resumen}

El presente artículo expone el primero de una serie de escritos inéditos del Siervo de Dios Eduardo Francisco Pironio, que él escribiera durante el año 1938, siendo seminarista y estudiando en el Seminario Mayor San José de la Arquidiócesis de La Plata. En ellos se pueden observar algunas temáticas que van a ser frecuentes luego en su predicación, como la amistad y la esperanza. Los artículos fueron originalmente editados en la revista "Sapientia", publicación histórica del seminario. El valor de estos textos radica en que permiten conocer un poco más a Pironio en su juventud, quien hoy está en proceso de ser beatificado.

Palabras clave: Pironio, cardenal, seminarista, amistad, esperanza, Sapientia, Virgen María, cuentos.

\section{Abstract}

The current article exposes the first of a set of unpublished writings that belong to the Servant of God Eduardo Francisco Pironio, that were written during 1938, when he was seminarist and was studying on the Mayor Seminary San Jose from the Archdiocese of La Plata. In them it's possible to observe some themes which are going to be frequent then in his predication, like friendship and hope. The articles were originally edited on the magazine "Sapientia", a Seminary's historical publication. The value of these texts lies in what they allow to know a little more to Pironio on his youngness, who today is in process of being beatified.

Keywords: Pironio, cardinal, seminarist, friendship, hope, Sapientia, Virgin Mary, tales. 


\section{REVISTA SAPIENTIA, AÑO II, N¹ - Fecha estimada: marzo de 1938 "DISPUTATIO" Y "QUAESTIO"}

Quienquiera se dedique al estudio del incomparable doctor, Santo Tomás de Aquino, o tan sólo conozca sus obras, encontrará dos entre las más importante del Aquinate: las "Quaestiones disputatae" y la inmortal "Summa theologica". Aun más: quienquiera se dedique al estudio de esta última o tan solo la hojee, advertirá por doquiera la palabra "Quaestio", encabezando cada uno de los problemas. ¿Por qué? Y aquí viene la cuestión. Antes de entrar en el estudio de la suma, es necesario indagar sobre el origen y significación de la palabra "Quaestio", para mejor comprender -dice Grabmann- el procedimiento de la exposición de la suma, y apreciar cada vez más la conexión íntima, existente entre esta obra y las "Quaestiones disputatae". El inmenso número de las obras del Aquinate se puede clasificar en dos grupos: las que tienen su origen en las clases y nacieron al calor de las aulas escolares, y las que nacieron del "trabajo académico" de S. Tomás, sin tener el origen en las clases, pero tendiendo siempre al aprovechamiento de sus discípulos. No en vano es el ángel de las escuelas, que procura tomar al alumno de la mano y guiarlo para que salga de sus clases entusiasmado por la doctrina mil veces santa de nuestra religión, e iluminado por los rayos luminosos que se escapan del incomparable sol de sabiduría, S. Tomás.

Y así enseña el ángel de las escuelas la sagrada teología en las facultades de París y de Roma. Su enseñanza la da en forma de lecciones, que son semejantes a las que tenemos en nuestros días, y en forma también de cuestiones, de las cuales vamos a hablar seguidamente.

En la Edad Media, se tomaba por el nombre de "quaestio", algo parecido a lo que nosotros llamamos mensuales, vale decir: disputas entre profesores y alumnos acerca de tesis escolares, fácilmente se verá luego la diferencia existente entre las antiguas "Quaestiones" y las actuales mensuales nuestras. Ayudaban estas disputas a despertar el interés y entusiasmo por la materia, y sobre todo a aclarar algunos puntos referentes a la misma. 


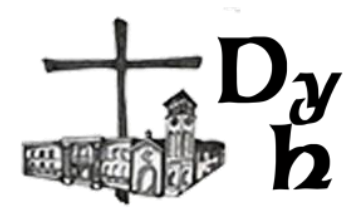

Pero estas disputas, verdaderamente y hablando con más precisión, no se llamaban "quaestio" sino más bien "disputatio". Las que realmente llevaban el nombre de "quaestio", eran las redacciones literarias de esas disputas, las actas, diríamos, de esas discusiones.

En una palabra: "disputatio" era el mismo acto de la discusión entre profesores y alumnos, y las "quaestio" eran las actas de esas disputas.

Ahora bien: entendido ya el significado de "disputatio" y "quaestio", vayamos a sus divisiones y desarrollo. Existía una clase de "disputationes" que se ejercitaban varias veces al año, con corto intervalo de unas a otras y que por lo mismo se denominaban "disputationes ordinariae". En ellas se discutía un tema cualquiera, visto ya en la clase, y se lo encaminaba en conexión con otros temas; es decir: se discutía sobre varios asuntos relacionados íntimamente los unos con los otros. Es lo que hacemos nosotros en nuestras mensuales: se nos presenta un conjunto de diez o doce tesis, pero todas eslabonadas y dirigidas a un asunto central: el problema del conocimiento o de la certeza, por ejemplo.

El célebre P. Mandomet y otros, nos dan una idea del modo como se efectuaban estas disputas. El tema sobre el cual versaba una "Disputatio Ordinaria", era uno, como se ha dicho antes, el cual se discutía en otra "Disputatio" próxima, sino se agotaba en la primera, extendiéndose a veces hasta un año entero y varios años también. Ordinariamente estas disputas duraban dos días: en el primero la labor era para el "defendeus" que solía ser un bachiller elegido entre muchos.

Bajo la protección de su profesor tenía que responder a todos los argumentos y objeciones presentados por otros profesores, bachilleres, o simples estudiantes.

Ya se ve, por lo tanto, que existe un gran parecido entre tales y disputas y nuestras mensuales. En ambos hay uno que defiende, y profesores y estudiantes que atacan y arguyen.

Esta era la labor del primer día.

En el segundo continuaba la disputa, pero no ya con el "defendeus", sino con el mismo profesor; la labor más en este día le tocaba a él.

Tomaba los argumentos que en contra del "defendeus" se habían presentado la víspera, los ordenaba y los iba respondiendo en "oponiendo como dice Grabmann- otros argumentos sacados de la razón y de la autoridad, 
y que presagiaban desde ya la definitiva solución del problema. Hecho esto de un modo general, entraba después en detalles hasta el fondo de la cuestión. Una vez allí, resolvía de todas maneras el problema, iba probándolo por detalles, hasta que terminaba con la solución definitiva que, por ser hecha por el profesor, o maestro, se llamaba "determinatio magistralis". Una vez llegado el profesor a esta solución importante, respondía a las objeciones que de nuevo le presentaban profesores o estudiantes.

Terminadas las objeciones, terminaba también la disputa. Resumiendo ahora para mayor intelección el proceso de esta larga y "Solemne ceremonia universitaria", se tiene: Primer día: un bachiller determinado de antemano responde, bajo la tutela del profesor, a los argumentos de profesores o estudiantes. Segundo día: el mismo profesor, opone argumentos a los argumentos presentados la víspera, prueba así su tesis y responde luego a las objeciones, terminando la disputa.

Finalizado el acto solemne de la "Disputatio ordinaria", viene el proceso escrito, o lo que llamaríamos acta de esta "disputatio".

En ellas no se hace más que escribir las diversas opiniones de los deliberantes y la solución definitiva del problema. Estas redacciones o actas, se denominaban "Quaestiones disputatae".

Ahora bien: además de las "disputatio" que acabo de exponer, había otra clase de disenciones menos importantes por su objeto y su frecuencia: son las "disputationes de quolli let" o "disputationes generales". No versaban sobre un asunto determinado como lo hacían las "disputationes ordinariae", es decir: no giraban alrededor de un tema central, sino que encaminaban cuestiones sin ninguna relación entre sí, sin ninguna conexión íntima.

Esto en cuanto al objeto; en cuanto a la frecuencia, que también he mencionado arriba, estas disputas se efectuaban tan solo dos veces al año: antes de Navidad, durante el Adviento, y antes de Pascua, durante la Cuaresma. Atendida esta división de tiempo en que se ejercitaban, estas disputationes, se denominaban respectivamente: "Disputationes Generales de natali", y "Disputationes Generales de pascha".

El desarrollo de estas disputas de Quodlitet se verificaba del mismo modo que el de las "Ordinariae"; de modo que es inútil repetir aquí todo el proceso. Ahora bien: ya lineas más arriba, he insinuado de algún modo la 


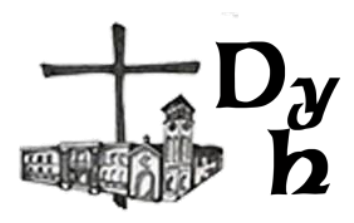

distinción entre estas "Disputationes generales" y las anteriormente consideradas "Disputationes Ordinariae".

En primer lugar, se distinguen en cuanto al objeto; en cuanto a la materia diríamos de éstas disputas: Las "Disputationes Ordinariae" versan sobre asuntos conexos entre sí y dirigidos a una idea o tema central. Por el contrario las "Disputationes de Quodlibet", como su mismo nombre lo indica, versan sobre cualquier tema pero sin unión alguna con otros que se tratan también; no existe la unidad perfecta que existe en las primeras "Disputationes".

Esta primera diferencia es en cuanto a la materia; la segunda es en cuanto a la forma. $Y$ en verdad: En las "Disputationes Ordinariae" se examina un asunto centra, pero bien a fondo, lo más profundamente posible, en tanto que en las otras "Disputationes" no se va tanto al fondo de los problemas; se los considera más bien, de un modo superficial.

Hay todavía una tercera diferencia que podríamos llamar secundaria: la frecuencia con que se hacen estas disenciones.

Las primeras, las "Disputationes Ordinariae", se llevan a cabo muchas veces al año mediante un corto intervalo. Las segundas, en cambio, las "Generales", tienen lugar nada más que dos veces al año y en tiempos más o menos determinados: en el Adviento y en la Cuaresma.

Ahora bien: así como las "Disputationes Ordinariae" eran redactadas después en forma de actas de denominábamos "Quaestiones disputatae", así también son redactadas las "Disputationes Generales", llevando esta redacción el nombre de "Quaestiones Quodlibetales", o "Quaestiones de Quodlibet", o simplemente "Quodlibeta".

Estas actas, "Quodlibeta" no contienen en sí ninguna diferencia formal de las "Quaestiones disputatae"; la única diferencia está en la materia que redactan, lo cual ya ha sido expuesto anteriormente. En efecto: no hacen más que reunir literariamente todo el largo proceso de las discusiones generales, anotando por último las soluciones definitivas de los problemas.

Resumiendo ahora, y ya para terminar, lo que hasta aquí llevo dicho, se nos presenta que: existe una diferencia entre las "Disputationes Ordinariae" y las "Disputationes Generales" en cuanto a la materia; otra en cuanto a la forma, y una tercera en lo tocante al tiempo. En efecto: las primeras tratan de asuntos 
varios pero íntimamente unidos (materia) y examinados con entera profundidad (forma), lo cual no se encuentra en las "Disputationes de Quodlibet". Además estas íntimas se verifican con mucha menor frecuencia (tiempo) que la otras. Por otra parte: las redacciones de respectivas disputas no se distinguen más que por la materia, cuya distinción acabo de exponer.

Y ahora quiero observar una cosa en lo tocante a la distinción de materia que he dado. Se podría objetar: la primera distinción es más bien formal que material, pues la unidad de los asuntos es más bien un aspecto formal. Bien y está puesto en razón esto último; pero no he querido referirme yo a la unidad como tal, sino más bien a los asuntos que exigen esa unidad, lo cual pertenece ya a la materia.

Eduardo F. Pironio 